2020-10-01

\title{
Developing policy and practice for marine net gain
}

Hooper, T

http://hdl.handle.net/10026.1/16464

10.1016/j.jenvman.2020.111387

Journal of Environmental Management

Elsevier BV

All content in PEARL is protected by copyright law. Author manuscripts are made available in accordance with publisher policies. Please cite only the published version using the details provided on the item record or document. In the absence of an open licence (e.g. Creative Commons), permissions for further reuse of content should be sought from the publisher or author. 


\title{
Developing policy and practice for marine net gain
}

\author{
Tara Hooper $^{*}$, Melanie Austen ${ }^{1}$ and Aisling Lannin ${ }^{2}$ \\ ${ }^{1}$ School of Biological and Marine Sciences, University of Plymouth, Drake Circus, Plymouth, PL4 8AA, UK \\ 2 Marine Management Organisation, Lancaster House, Hampshire Court, Newcastle Upon Tyne, NE4 7YH, UK \\ *corresponding author: tara.hooper@plymouth.ac.uk
}

\begin{abstract}
Policies that require development projects to ensure no net loss (NNL) of biodiversity are becoming common globally. Momentum is increasing to extend this concept to one of net gain, including for the marine environment. While such policies are being formulated it is important to learn the lessons from NNL approaches and consider the wider opportunities presented by a net gain strategy. The vehicle for NNL is typically the mitigation hierarchy, which is applied through planning consents and licensing to projects expected to have significant environmental impact. However, it becomes clear that significant marine net gain is unlikely to be achieved by following this approach. Attempting site-based like-for-like compensation, restoration and enhancement is likely to result in only a minimal contribution towards aspirations for environmental recovery and addressing the climate and biodiversity crises. Moving forward with an effective net gain strategy will be a complex process, with challenges that range from a lack of data to the limitations presented by existing governance frameworks. In particular, the inadequate treatment of cumulative effects within the Environmental Impact Assessment process, and how regional marine planning can be better used to translate strategic objectives to the site level, need to be addressed. Taking the broader perspective of environmental (as opposed to biodiversity-only) net gain, and linking this to the natural capital approach offers advantages, and it is also essential that marine net gain considers species as well as habitats. Widespread marine net gain cannot occur independently of fisheries management, and extensive public engagement and stakeholder co-production is required to develop the necessary collaborative solutions.
\end{abstract}

\section{The policy context}

Governments are responding to the global climate and ecological crises by committing to policies of nature improvement and restoration, for example in the UK 'A Green Future: Our 25 Year Plan to Improve the Environment' (HM Government 2018). Various approaches are being implemented to improve the state of nature, including strategic government-led programmes such as spatial planning and increasing coverage by protected areas. At a local site-based level, focus has been on maintaining the state of the environment within the 
footprint of an infrastructure project or licensed activity (hereafter referred to as 'developments') by applying the EU Environmental Impact Assessment, Habitats, and Birds Directives. Indeed, policies that require developments to ensure no net loss (NNL) of biodiversity are becoming common globally (Maron et al., 2016). These are supported by the concept of the mitigation hierarchy (Figure 1), which is typified by UK national planning policy "if significant harm to biodiversity resulting from a development cannot be avoided (through locating on an alternative site with less harmful impacts), adequately mitigated, or, as a last resort, compensated for, then planning permission should be refused' (MHCLG, 2019, para 175a). This principal exists in the policies of at least 15 countries including South Africa, Columbia and Mozambique as well as North America and Europe (Niner et al., 2017a). However, despite this approach the state of the environment continues to decline and increasingly governments are proposing methods whereby developers not only reduce their environmental impact but actively improve nature.

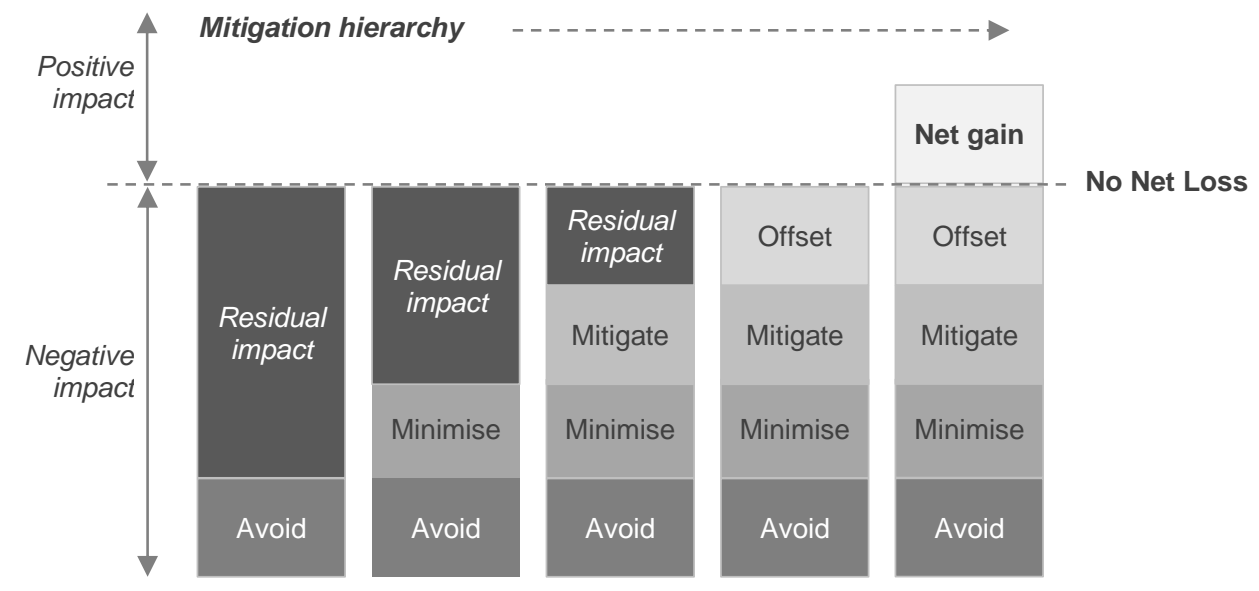

Figure 1. The mitigation hierarchy, including net gain (adapted from Rio Tinto, 2008)

Policies that seek to extend the NNL concept to one of net gain (i.e. positive environmental impact) exist in countries including France and Chile (Maron et al., 2018), and the UK Government has announced that forthcoming legislation will mandate biodiversity net gain as a requirement for new developments on land that fall within local planning jurisdiction (Defra, 2019). Achieving NNL is not without significant difficulties and controversies (Berges et al., 2020; Quétier et al., 2014; Maron et al., 2016) and the further challenge of progression to net gain should not be underestimated (Bull and Brownlie, 2017). This is particularly true for the marine environment, but documented aspirations for marine net gain are emerging in policies such as the UK Marine Plans (MMO, 2020a). This is despite the concept being untested and unevaluated in practice, without indications of how much contribution such a policy can make to the required significant restoration and improvement of nature. This 
review therefore explores a series of questions that need to be answered in order to implement effective net gain policies for the marine environment, using the UK as the primary case study to provide specific policy examples.

\section{Are there clear lessons from existing No Net Loss policies?}

Nearly 80 nations have policies that enable measures to compensate for impacts in the marine environment, although in only 15 countries have these progressed beyond the initial stages of defining goals and objectives and exploring implementation mechanisms (Shumway et al., 2018). Despite the increasing number of marine NNL policies, extensive reviews of the literature have had little success in finding many examples of practice (Bull and Strange, 2018). Where such initiatives do exist, measures tend to be limited to a subset of keystone species and/or specific protected features, particularly seagrass, mangroves and coral reefs (Bas et al., 2016; Jacob et al., 2016). Evidence of monitoring and evaluation is also lacking, making it difficult to determine the effectiveness of specific policies (Shumway et al., 2018). Even in academic studies, the duration of monitoring in marine restoration projects is usually far below that required to assess effectively whether recovery has been achieved (Jacob et al., 2018).

There is also evidence that the mitigation hierarchy is not being followed in practice. A detailed review of environmental impact assessments for developments in French waters found that offsetting (the final step of the hierarchy) was implemented ahead of avoidance and mitigation, but that even offsetting was rarely undertaken, being the aim of only $7 \%$ of the proposed measures (Jacob et al., 2016). Evidence of routine independent monitoring and evaluation, of both application of the mitigation hierarchy and post consent monitoring of environmental state, is not apparent. It is particularly important that avoidance is given the necessary priority in the marine environment, as offsetting is often high risk and high cost (Shumway et al., 2018). Clear recognition of the need to establish avoidance areas is often lacking in legislation, however (Tallis et al., 2015). The EU Marine Spatial Planning Directive acknowledges the importance of reducing pressure on the marine environment, but in the UK activities are not confined to specific zones nor are there designated areas where no activities occur.

At present, assessment of the likely ecological losses from a development, and the potential gains from any offsetting, rely primarily on expert judgement, and the measures proposed may be inappropriate and questionable in terms of their ecological equivalence (Bas et al., 2016; Levrel et al., 2012). Conclusions from wide-ranging reviews suggest that improvements are required in the way avoidance measures are described, impact reduction 
is monitored, and mitigation is enforced (Jacob et al., 2016). There is also a lack of guidance for mitigation requirements in the marine environment, as opposed to wetlands, for which such literature does exist (Jacob et al., 2018). Where aspirations are moving towards net gain, clear statements are needed that define policy principles, desired outcomes, and the scope of application in order to inform practical approaches (Bull and Brownlie, 2017).

\section{Should the net gain principle apply only to biodiversity?}

Globally, including for the proposed UK legislation for developments on land, the focus of NNL and net gain policies is biodiversity (Maron et al., 2018; Defra, 2019). However, there are increasing calls for net gain policies to apply more widely, including arguments that net gain based on site-specific biodiversity alone will deliver fewer ecological benefits than if the approach considered the wider, integrated environmental system (Natural Capital Committee, 2019a). Societal implications should also be better addressed. The link between environmental interaction and wellbeing is increasingly well documented (e.g. White et al., 2019), and risks to wellbeing occur where local people's access to ecosystem services is restricted by either the development itself or the measures implemented to mitigate or offset its environmental impact (Jones et al., 2019). A "no worse off" societal principle to sit alongside biodiversity NNL has already been proposed (Griffiths et al., 2019), and the development of holistic net gain policies provides the opportunity to increase benefits and create equity for those people who currently lack access to high quality outdoor environments (Natural Capital Committee, 2019a). England's 25 Year Environment Plan (HM Government, 2018) and the UK's Industrial Strategy (HM Government 2017) both have human wellbeing as fundamental goals of their vision and ambition.

Draft marine plans for England are promoting a wider approach with the expectation that "environmental net gain for marine or coastal natural capital assets and services" will be delivered as compensation by proposals that may have significant adverse environmental impacts (MMO, 2020a, p44). Environmental net gain is, however, not precisely defined, and is instead described as "an evolving concept that will expand biodiversity net gain approaches to include wider benefits" (MMO, 2020b, p247), with the further clarification that measures to deliver net gain can include increasing ecosystem service provision; improving natural capital assets; removing threats or preventing decline; and the restoration, improvement or creation of natural capital assets and services (MMO, 2020b). Specific examples of opportunities to create net environmental and social gains include co-location of sectors such as aquaculture and/or sea angling with offshore renewables; better design of hard structures to enhance marine biodiversity; subsidising transition to more sustainable 
fisheries; and sustainable shellfish aquaculture that simultaneously improves water quality and associated biodiversity (Natural Capital Committee, 2019b).

\section{How will net gain be measured?}

Implementing standards for approaches and interventions increases comparability between, and confidence in, the outcome of assessments. International standards exist in different forms, including through environmental, social and governance benchmarks used primarily in relation to investment and corporate social responsibility. The sustainability framework of the World Bank Group's International Finance Corporation, for example, has performance standards against which its clients' projects are assessed. Performance Standard 6, on biodiversity conservation and sustainable management of living natural resources, includes the principles of NNL and net gain (IFC, 2019). Methodological standards are also being developed for aspects of the natural capital approach (particularly accounting), such as the United Nations System for Environmental Economic Accounts. Marine-specific standards can be slower to emerge than those for terrestrial systems, however. While the UK's Natural Capital Accounts now incorporate regulating services such as carbon sequestration, marine ecosystems are not included within these estimates (ONS, 2019).

At present, standardised protocols for monitoring offsets in the marine environment are lacking (Jacob et al., 2016). There are different methods by which environmental losses and gains can be measured including Habitat Equivalency Analysis (HEA), an approach used widely in the United States and Europe, usually in the context of determining compensation for pollution events (Dunford et al., 2004; Desvousges et al., 2018). Metrics designed explicitly for the application of net gain to land management practices and infrastructure developments include the UK's Biodiversity 2.0 Metric (Crosher et al., 2019), which provides a quantitative score for the change in 'biodiversity units' based on a comparison of the type, area, quality, ecological connectivity and strategic significance of habitats between the baseline situation and post-intervention scenarios. By including parameters on extent, condition and spatial configuration, the metric is compatible with suggested approaches for monitoring natural capital assets (as proposed in e.g. Natural Capital Committee, 2017; Mace et al., 2015).

As yet, there does not appear to be a marine protocol with the same level of methodological detail as the terrestrial approach. A conceptual framework for developing a similar biodiversity metric for the marine environment has recently been proposed that considers habitat type, distinctiveness and condition (ABPMer, 2019). Unlike its terrestrial equivalent, which uses broad habitat categories as a proxy for species communities (Crosher et al., 
2019), the marine framework also proposes an explicit species metric. This recognises that there are impacts on species that do not have implications for habitats (ABPMer, 2019). While this is also true in the terrestrial environment, the importance of fisheries and highly mobile marine fauna in general mean that it is essential that individual species or species groups are also considered in marine net gain. Methods proposed for other purposes may also provide useful insights; Derous et al. $(2007 a, b)$ developed a somewhat data-intensive method described as marine biological valuation, which considers rarity, aggregation-fitness consequences, naturalness and proportional importance of species and their ecological characteristics within marine subzones.

The more factors that need to be included in a net gain framework, the more complex the decision-making process, but one-dimensional approaches are inadequate for addressing complex environmental problems (Kirschke and Newig, 2017). In particular, such single metrics may mask significant ecological change. For example, artificial reefs placed on sandy seabeds are likely to increase the biodiversity of an area, but they will not compensate for the sedimentary habitat that is lost (Elliott et al., 2007). There is therefore a risk that a simple biodiversity summary metric would show only the overall gain. The Uniform Mitigation Assessment Method (UMAM), designed as a standard assessment framework for any type of impact and mitigation for Florida wetlands, provides scores based on a suite of indicators for each of three categories (Bardi et al., undated) and so goes some way towards a more multi-criteria approach. Bas et al. (2016) have proposed a similar framework for marine areas that includes a suite of indicators within the categories of physio-chemical structure, biological structure, and ecosystem functionality.

A multi-criteria approach is more compatible with the movement towards environmental (as opposed to biodiversity) net gain policies. Wider frameworks for the assessment of ecosystem services (Tallis et al., 2015) and social impacts (Jones et al., 2019) alongside biodiversity targets for NNL have been proposed within the academic literature, but not yet applied in support of specific decision making. In the UK, there is ongoing work on an 'EcoMetric' to provide ecosystem service assessments in the context of land use planning, although the final version of this is not yet available (Nayak and Smith, 2019). Like the UK's Biodiversity 2.0 metric, which it is designed to complement, the Eco-Metric is expected to include coastal but not marine habitats, as they are outside the scope of the planning framework to which these tools pertain. Net gain regulations that will be implemented via the UK's Royal Town and Country Planning Act are bounded by the lowest astronomical spring tide (and thus cover large coastal areas as well as significant estuaries). 
While accepted guidelines for the implementation, in practice, of a net gain approach that encompasses marine biodiversity, natural capital assets and ecosystem services do not yet exist, relevant assessment frameworks that may provide a starting point have been proposed within academic literature. Methods for the general assessment of marine natural capital and ecosystem services include approaches such as asset and risk registers, which have been recently reviewed in Hooper et al. (2019) with initial testing undertaken in real situations, for example by Rees et al. (2019). However, these require further appraisal for their application to the specific context of mitigating development impacts and supporting net gain. Significant efforts have also been made to identify appropriate indicators for marine ecosystem services (including by Atkins et al., 2015; Hattam et al., 2015; and Broszeit et al., 2017).

Many of these suggested marine ecosystem service indicators (and those proposed specifically for ecological NNL monitoring such as by Bas et al., 2016) are consistent with descriptors for European Union environmental directives and/or with data known to be used within typical Environmental Impact Assessments. This deliberate alignment aims to increase the likelihood that proposed indicators can be used in practice, and recognises the realities of limitations in data availability for the marine environment. Even while new metrics for marine net gain are being proposed, it has been noted that "addressing aspects such as habitat disturbance and species impacts in the marine environment in a robust and equitable way remains problematic at this time" (ABPMer, 2019, p1). Best practice for evaluating marine habitat recovery should include at least five years of monitoring (Jacob et al., 2018). However, the statutory monitoring of marine infrastructure developments in the UK has been heavily criticised (Walker et al., 2009; Walker and Judd, 2010), from which lessons need to be learned as net gain protocols develop.

\section{What are appropriate net gain targets?}

The frames of reference (baselines and counterfactuals) against which conservation objectives are measured are of fundamental importance to the actual and perceived outcomes of interventions, but often these are not clearly stated in NNL and net gain policies (Bull et al., 2014). The reference scenarios can also be very different depending upon whether the outcome relates to an overarching policy goal of NNL across a jurisdiction or to an impact-specific target with a narrower scope (Maron et al., 2018). Ambitions such as that in the UK's 25 Year Environment Plan to "leave our environment in a better state than we found it" (HM Government, 2018, p6) will need to be more clearly defined and to be supported by more specific targets for the different components required in the delivery of net gain. These targets should be based on a reference framework that, as a minimum, 
considers both ongoing trends in environmental change and human impacts, and clearly articulates the counterfactuals against which the policy is to be assessed (Bull et al., 2014).

The choice of reference framework is not necessarily straightforward. Dramatic transformations of near-shore, estuarine and continental shelf environments in the North Sea as a result of over-exploitation and fishing techniques had already occurred more than a century ago (Thurstan et al., 2013; Bennema et al., 2020), and biogenic reefs were similarly lost from coastal areas of North America and Australia during the $19^{\text {th }}$ and $20^{\text {th }}$ centuries (Kirby, 2004; Alleway and Connell, 2015). Restoration on the scale necessary to compensate for these losses seems unlikely, not least because our collective lack of memory of the original extent and condition of marine habitats and species populations means our expectations of ecosystem potential are reduced (Alleway and Connell, 2015); a concept originally termed 'shifting baselines' (Pauly, 1995). Furthermore, the reestablishment of historic ecosystems would require a radical transformation of current environmental practise (Thurstan et al., 2013).

The costs of large scale active restoration are also likely to be prohibitive. Average per hectare costs (including capital and operating costs) for the restoration of coastal habitats have been reported at US $\$ 80,000$ to US $\$ 1,600,000$ (Bayraktarov et al., 2016). Conversely, maximum values for the acquisition and management of terrestrial protected areas are in the range of US $\$ 10,000$ to US $\$ 50,000$ per hectare (Armsworth, 2014). The high costs of marine restoration have been attributed to the inaccessibility of the environment, and fewer opportunities for community and volunteer-based projects (Bayraktarov et al., 2016). This high cost is perhaps a contributing factor in the observed decline in the level of restoration activity in the United States following economic downturn, although in China (where restoration efforts are overwhelmingly government-led), the number of coastal and marine habitat restoration projects has continued to increase over time (Li et al., 2019).

Even for the smaller scale, there is a lack of evidence that restoration efforts to offset impacts actually achieve NNL or provide measurable gains in the marine environment (Shumway et al. 2018; Elliott et al., 2007). Attempts to restore marine habitats often suffer from poor design and a lack of independent review, while metrics for their success usually focus on survival and growth rates, and fail to consider biodiversity indicators or evaluate ecosystem function (Jacob et al., 2018). Therefore, pilot studies with stringent evaluation would be required to determine the significance of site-level restoration and offsetting for net gain, which should also be compared to alternative nature recovery strategies. 
More appropriate, perhaps, than a reference framework that focuses solely on remediating specific habitat loss is a forward-looking perspective that considers the need to provide, equitably and sustainably, for a growing demand for resources from ecosystems that are shifting under climate change (Apitz, 2013). A net gain framework that includes social and ecosystem service implications as well as environmental impacts may therefore better support the definition of appropriate net gain strategies. For example, the artificial reefs created by built infrastructure such as offshore wind farms will not replicate historical shellfish reefs, but they have the potential to support some of the lost ecological functioning and certain ecosystem services (Hooper et al., 2017). Projects have also explored how these artificial reef effects could be augmented through nature-inclusive design, which is now obligatory for newly built offshore wind farms in, for example, the Netherlands (Bureau Waardenburg, 2020). Engineering solutions that provide biodiversity and ecosystem service benefits without compromising the function or integrity of coastal defence structures have also been proposed (e.g. Firth et al., 2014). A directory that details relevant attributes of available ecological engineering techniques (such as performance criteria, uncertainty, costs, and feasibility) would support the development of net gain strategies for infrastructure developments (Jacob et al., 2016), and has recently been attempted for offshore wind structures (Prusina et al., 2020). However, caution should be exercised in promoting artificial reefs as part of net gain solutions, to avoid their use as 'greenwash' for wider environmental damage (Firth et al., 2020).

There are further net gain opportunities around offshore built infrastructure, such as the exclusion of bottom trawling from the site. This provides a passive restoration option (through the removal of pressures), which, due to the difficulties of active restoration, is often a more appropriate solution offshore (Jacob et al., 2018). Additional active options could nonetheless be explored through, for example, seeding the area between offshore wind turbines (now undisturbed by trawling) with species such as native oysters or seagrass where the conditions are appropriate.

\section{What is the appropriate scope, scale and policy framework for net gain?}

In countries such as the UK, applying marine net gain to built infrastructure developments, such as offshore windfarms, would be most analogous to the current terrestrial approach, and the legislative framework for the attachment of conditions to consents and licences is already in place. However, a recent review of Environmental Impact Assessments for offshore wind farms across Europe showed that the impacts of individual projects are usually considered negligible, offset by the positive benefits of artificial reef effects, or less negative 
than counterfactual scenarios, and so additional actions to offset impacts on specific marine features are not required or enforced (Vaissière et al., 2014).

For offshore wind farms, cumulative impacts (both positive and negative) are expected to become increasingly significant as European countries seek five-fold growth in installed capacity by 2030 , and are predicted to require between ten and twenty times the current capacity by 2050 (Wind Europe, 2020). As well as the potential displacement of fishing activity, there are particular concerns about far-field negative impacts of offshore windfarms on the hydrodynamic regime (Cazenave et al., 2016) and as vectors for the spread of invasive species (Adams et al., 2014; Janßen et al., 2013). The potential positive impacts over a larger scale (such as from increasing coverage by artificial reefs) have yet to be assessed. The need for effective definition of the activity-, pressures- and effects-footprints of human activities across different scales is required for successful marine management (Elliott et al, 2020). At present, however, cumulative impacts are poorly addressed in Environmental Impact Assessment for marine developments (Jacob et al., 2016).

Given this combination of the impacts of individual developments being below the threshold for offsetting, and the inadequate treatment of cumulative effects, the opportunities for generating significant marine net gain through existing consenting approaches (as they operate currently) are likely to be limited. Furthermore, even where policies and legislation exist, the standard of Environmental Impact Assessment varies in practice internationally. In Columbia, for example, which has been used as a case study of middle-income countries, the environmental licensing process is inconsistent, fragmented, and has been eroded in the past when government changed (Pereira et al., 2019). Such existing weaknesses would need to be addressed if net gain approaches were to be successful. Also, the scale of built infrastructure offshore is small compared to that of land-based developments. Therefore, detailed feasibility studies are needed that consider the cost effectiveness of a site-based net gain approach in terms of the resource required to implement and manage such a programme compared to the likely environmental returns.

Mechanisms such as Strategic Environmental Assessment and regional marine planning are likely to be particularly important in understanding the extent of positive and negative impacts beyond those for individual sites, and hence exploring opportunities for strategic (as opposed to site-level) net gain. Improved connection between these larger-scale, strategic assessments and the licensing of individual developments will be required if net gain policies are to be effective. The idea of applying the mitigation hierarchy at an ecosystem (as opposed to a site-only) level has been explored in the context of port developments in 
Ghana (de Boer et al., 2019), and there have been calls for the approach to impact assessment in Columbia to evolve from the focus on single interventions to a wider perspective at a regional scale (Pereira et al., 2019). In practice, governance across interconnected scales is not straightforward. Countries in Europe are exploring integrated marine governance, but not only do these approaches remain at an initial stage, they raise questions of legitimacy (van Tatenhove, 2011).

Overarching policies that consider the larger scale are nonetheless particularly appropriate given the high connectivity in the marine environment, and the need for an ecosystem-based approach, has already been emphasised in a scoping study for marine biodiversity offsetting in the UK (Dickie et al., 2013). However, few existing marine policies discuss explicitly how species' ranges and demography should affect the location of offsets (Shumway et al., 2018). Recommendations for net gain in terrestrial systems suggest that the choice of location for any offsetting should maximise ecological gains, deliver a coherent national network, provide benefits to people whose current environmental interaction opportunities are of a low quality, and be as close to the impact site as possible (Natural Capital Committee, 2019a). In the marine environment, however, it has been proposed that spatial flexibility should be encouraged in offsetting strategies. Allowing offsets to be disconnected spatially from the site of impact has the potential to improve outcomes and increase the likelihood of NNL (through increasing protection for key habitats necessary during the lifecycle of migratory species, for example), although this is balanced by risks that include difficulties in determining equivalence, complexity in implementation and governance, and the potential exacerbation of social inequality (Shumway et al., 2018).

Built infrastructure developments are not the only activities that occur in, or affect, the marine environment, and so the scope of net gain policies should extend to wider maritime uses. Mining and aggregate extraction are also managed within the consents and licencing framework, which would suggest that any net gain approach adopted within that process could also apply to these activities. However, investigations of areas of the North Sea have shown recovery to a natural state after aggregate extraction may be limited (Mielck et al., 2019), and a cost benefit analysis undertaken for a site in the UK's Thames estuary showed that active restoration is not economically viable (Cooper et al., 2013). Researchers have gone further to suggest that in the case of deep-sea mining it is not possible to achieve even NNL through the mitigation hierarchy due to the vulnerability of the habitats (Niner et al., 2018). The recovery of individual sites depends on the specific conditions (Foden et al., 2009) but the available evidence suggests that on-site net gain would not be feasible for 
mining and aggregate extraction, providing further support for policies that include spatial flexibility.

Financial compensation is an accepted option where environmental impacts cannot be avoided or mitigated (Wilkinson, 2009), and such contributions are often pooled for allocation to strategic environmental projects (Niner et al., 2017b). The UK provides an example of this, with a proportion of the revenue from its Aggregates Levy being placed in the Aggregates Levy Sustainability Fund (from 2002-2011), which included a dedicated marine allocation. Terrestrial projects supported by the fund included initiatives with direct ecological and social benefits (Natural England, 2010), but the marine funding was used primarily for scientific research rather than any active restoration or other environmental protection or enhancement (CEFAS, 2006; Hansard, 2009). The Aggregates Levy continues to be collected (although was under review in 2019) but the sustainability fund was ended in 2010 "in light of a very tight spending context and the need to reduce the deficit" (HM Treasury, 2019). Achieving net gain through levies and similar offsetting payments will not be possible without appropriate governance of the funds.

It will also be difficult to achieve any substantial marine net gain if fisheries are not considered. The direct and indirect environmental impacts of fisheries on the diversity and structure of benthic and pelagic communities are well known and widely documented (e.g. Jennings and Kaiser, 1998). These impacts are primarily addressed though quota management systems (to address over-exploitation of stocks); discard bans and gear modifications (to tackle by-catch); and the designation of marine protected areas (MPAs) within which harmful activities are prohibited (to reduce habitat damage). However, MPA strategies are known to have significant leakage issues (where the problem is merely displaced elsewhere) and achieving the limitations on fishing activities that are likely to be needed for widespread net gain may require a reduction in total effort through, for example, the buy-back of licences or through incentives for adopting alternative practices (MilnerGulland et al., 2018; Shumway et al., 2018). Effort reduction strategies must be considered carefully in their wider context, so as not to conflict with objectives for food security, employment, or the preservation of cultural heritage. In addition, the marine environment is affected by activities on land, particularly through the impacts of agricultural run-off and sewage discharge on water quality. Broad, flexible net gain systems that can accommodate marine and terrestrial activities could prove more effective in mediating complex impacts (Shumway et al., 2018). 
It becomes apparent that real net gain (in terms of truly significant enhancement of the marine environment) requires a systems approach, with site-based solutions fitting into a wider delivery structure for nature recovery. This requires cooperation and coordination in agreeing frames of reference and targets, carrying out monitoring and evaluation, and in allowing adaptive management in response. From the governance perspective, implementing a site-based marine net gain approach following the terrestrial model would be relatively straightforward, as it would fall within established systems for marine licensing. Putting in place an ambitious, co-ordinated, systems-based approach to net gain is a much more difficult proposition. It has already been argued that marine governance, in the UK at least, is overly complex with too many agencies involved in management and a lack of coordination resulting from organisations having overlapping remits and/or insufficient capacity to consider sectors beyond their own (Boyes and Elliott, 2015). The institutional challenges of adaptive management have also been documented (Rist et al., 2013). The requirements for an effective governance structure will therefore need to be considered alongside the technical aspects of achieving net gain. Attempting greater integration with terrestrial management is likely to add additional governance challenges, although some mechanisms already exist to support cooperation between agencies with land-based and marine jurisdictions. The UK's Coastal Concordat (HM Government, 2020) is one example but both its scope (the appointment of a single lead authority for planning applications) and uptake have been limited.

This wide range of actors with the ability to influence a possible net gain approach, as well as those affected by changes to marine policy and management, suggests that significant co-design and co-production will be required as the process develops. The frames of reference set for NNL and net gain affect how participants respond, their motivation to act, and how the costs and benefits are distributed (Bull et al., 2014). The perception of tradeoffs and the scope for utility transfer are also important considerations in brokering net gain agreements (Kyriazi et al., 2015). Engagement with the wider public is also important, in order to raise awareness of marine environmental issues and empower people in their role as environmental custodians with the capacity to hold authorities to account. The absence of offsetting by offshore wind farm projects has been attributed in part to a lack of public pressure because, while people are concerned about visual impact, they generally have no awareness of the subsurface impacts of developments (Vaissière et al., 2014). Many models already exist for collaborative approaches to conservation. The UK Environment White paper (HM Government, 2011) provided a framework for partnership projects for landscape-scale terrestrial nature enhancement through the designation of Nature Improvement Areas (NIAs). Similar mechanisms could be employed to bring together maritime users, 
conservation agencies and regulators to adopt a place-based net gain philosophy and lay the foundations for greater ambition in marine environmental protection.

\section{Conclusions}

From current practice under policies that are (at least nominally) no net loss, it becomes clear that significant marine net gain will not be achieved by attempting site-based like-forlike compensation, restoration and enhancement using existing consents and licensing processes as the primary delivery vehicle. Therefore, developing a metric by which biodiversity change can be documented adequately should not be the immediate focus for marine net gain. Instead, there is the need for a wide-ranging conversation on what, exactly, is meant by net gain and what opportunities the pursuit of this approach presents for the marine environment. The situation is analogous to that of natural capital accounting, for which the World Bank-led WAVES global partnership has emphasised the need to move from a focus on methods, data and single "magic bullet" solutions, towards a more decisioncentred approach that enhances opportunities for wide engagement and improved policy discourse, and utilises a range of tools (Vardon et al., 2017).

The lack of evidence of success from NNL policies does not preclude the adoption of net gain as a conceptual philosophy for marine management. Existing policy that seeks only to maintain conservation features in a 'favourable' condition lacks the ambition necessary to secure the sustainable management of marine systems (Rees et al., 2020). Net gain shifts the focus to one of active improvement rather than acceptance of the status quo, and thus has an important role to play. However, moving forward with an effective net gain approach will be a complex process, with challenges that range from a lack of data to the limitations presented by existing governance frameworks. In particular, the inadequate treatment of cumulative effects within the Environmental Impact Assessment process, and how regional marine planning can be better used to translate strategic objectives to the site level, need to be addressed.

Taking the broader perspective of environmental (as opposed to biodiversity-only) net gain offers advantages including opportunities to improve ecosystem service delivery and address social inequality. It is also essential that marine net gain considers species as well as habitats. Widening the scope of net gain adds to the complexity of the decision-making process, but single metrics alone are not appropriate as they can mask the significance of individual costs and benefits. Widespread marine net gain cannot occur independently of fisheries management, and extensive public engagement and stakeholder co-production is required to develop the necessary collaborative solutions. 
The priorities for future scoping studies are detailed assessments of specific contexts and scenarios in order to develop operational frameworks for net gain. These would include incorporating the natural capital approach, determining appropriate frames of reference, and exploring nested scales and integrated governance. Additional, field-based pilot studies will also be necessary to determine appropriate evaluation metrics and their data requirements, and to establish monitoring protocols. Monitoring and evaluation will be essential in order to determine how net gain approaches (in the context of their relative administrative complexity, cost and resource intensity) contribute in practice to the urgent priority for large-scale habitat and species restoration across fisheries, the coast, and pelagic and benthic ecosystems.

\section{Acknowledgements}

This work was funded by the Natural Environment Research Council through the South West Partnership for the Environment and Economic Prosperity (SWEEP; grant NE/P011217/1).

\section{References}

ABPMer. (2019). Net Gain. Moving towards a practical framework and metric for the marine environment. http://www.abpmer.co.uk/buzz/white-paper-adapting-net-gain-for-themarine-environment/

Adams, T., Miller, R., Aleynik, D. and Burrows, M. (2014). Offshore marine renewable energy devices as stepping stones across biogeographical boundaries. Journal of Applied Ecology, 51: 330-338.

Alleway, H. K., \& Connell, S. D. (2015). Loss of an ecological baseline through the eradication of oyster reefs from coastal ecosystems and human memory. Conservation Biology, 29(3), 795-804.

Apitz, S. E. (2013). Ecosystem services and environmental decision making: Seeking order in complexity. Integrated Environmental Assessment and Management, 9(2), 214-230.

Armsworth, P. R. (2014). Inclusion of costs in conservation planning depends on limited datasets and hopeful assumptions. Annals of the New York Academy of Sciences, 1322(1), 61-76.

Atkins, J. P., Burdon, D., \& Elliott, M. (2015). Identification of a practicable set of ecosystem indicators for coastal and marine ecosystem services. In Coastal Zones Ecosystem Services (pp. 79-102). Springer, Cham.

Bardi, E., Brown, M.T., Reiss, K.C. and Cohen, M.J. (undated). UMAM. Uniform Mitigation Assessment Method Training Manual. Web-based training manual for Chapter 62-345, FAC for Wetlands Permitting. Howard T. Odum Centre for Wetlands, University of Florida and Florida Department of Environmental Protection. ttp://sfrc.ufl.edu/ecohydrology/UMAM_Training_Manual_ppt.pdf 
Bas, A., Jacob, C., Hay, J., Pioch, S., \& Thorin, S. (2016). Improving marine biodiversity offsetting: a proposed methodology for better assessing losses and gains. Journal of environmental management, 175, 46-59.

Bayraktarov, E., Saunders, M. I., Abdullah, S., Mills, M., Beher, J., Possingham, H. P., Mumby, P.J. and Lovelock, C. E. (2016). The cost and feasibility of marine coastal restoration. Ecological Applications, 26(4), 1055-1074

Bennema, F. P., Engelhard, G. H., \& Lindeboom, H. (2020). Ostrea edulis beds in the central North Sea: delineation, ecology, and restoration. ICES Journal of Marine Science. doi:10.1093/icesjms/fsaa134

Berges, L., Avon, C., Bezombes, L., Clauzel, C., Duflot, R., Foltête, J. C., Gaucherand, S., Girardet, X. and Spiegelberger, T. (2020). Environmental mitigation hierarchy and biodiversity offsets revisited through habitat connectivity modelling. Journal of Environmental Management, 256, 109950.

Boyes, S. J., \& Elliott, M. (2015). The excessive complexity of national marine governance systems-Has this decreased in England since the introduction of the Marine and Coastal Access Act 2009?. Marine Policy, 51, 57-65.

Broszeit, S., Beaumont, N. J., Uyarra, M. C., Heiskanen, A. S., Frost, M., Somerfield, P. J., ... \& Austen, M. C. (2017). What can indicators of good environmental status tell us about ecosystem services?: Reducing efforts and increasing cost-effectiveness by reapplying biodiversity indicator data. Ecological indicators, 81, 409-442.

Bull, J. W., \& Brownlie, S. (2017). The transition from No Net Loss to a Net Gain of biodiversity is far from trivial. Oryx, 51(1), 53-59.

Bull, J. W., \& Strange, N. (2018). The global extent of biodiversity offset implementation under no net loss policies. Nature Sustainability, 1(12), 790-798.

Bull, J. W., Gordon, A., Law, E. A., Suttle, K. B., \& Milner-Gulland, E. J. (2014). Importance of baseline specification in evaluating conservation interventions and achieving no net loss of biodiversity. Conservation Biology, 28(3), 799-809.

Bureau Waardenburg. (2020). Options for biodiversity enhancement in offshore wind farms. Knowledge base for the implementation of the Rich North Sea Programme. Bureau Waardenburg Rapportnr.19- 0153. Bureau Waardenburg, Culemborg.

Cazenave, P. W., Torres, R., \& Allen, J. I. (2016). Unstructured grid modelling of offshore wind farm impacts on seasonally stratified shelf seas. Progress in oceanography, 145, $25-41$.

CEFAS. (2006). Aggregate Levy Sustainability Fund Marine Environment Protection Fund. https://www.cefas.co.uk/publications/marketing/alsf.pdf

Cooper, K., Burdon, D., Atkins, J. P., Weiss, L., Somerfield, P., Elliott, M., ... \& Vivian, C. (2013). Can the benefits of physical seabed restoration justify the costs? An assessment of a disused aggregate extraction site off the Thames Estuary, UK. Marine pollution bulletin, 75(1-2), 33-45.

Crosher, I., Gold, S., Heaver, M., Heydon, M., Moore, L., Panks, S., Scott, S., Stone, D., and White, N. (2019). The Biodiversity Metric 2.0: Auditing and accounting for biodiversity 
value: technical supplement (Beta version, July 2019). Natural England Joint Publication JP029. http://publications.naturalengland.org.uk/publication/5850908674228224

de Boer, W. P., Slinger, J. H., Vreugdenhil, H. S., Taneja, P., Appeaning Addo, K., \& Vellinga, T. (2019). Identifying Ecosystem-Based Alternatives for the Design of a Seaport's Marine Infrastructure: The Case of Tema Port Expansion in Ghana. Sustainability, 11(23), 6633.

Derous S., Austen M., Claus S., Daan N., Dauvin J., Deneudt K., Depestele J., Desroy N., Heessen H., Hosten K., Marboe A. H., Lescrauwaet A.-K., Moreno M. P., Moulaert I., Paelinckx D., Rabaut M., Rees H., Ressurreicao A., Roff J., Santos P. T., Speybroeck J., Stienen E. W. M., Tatarek A., Hofstede T., Vincx M., Zarzycki T., Degraer S. (2007). Building on the concept of marine biological valuation with respect to translating it to a practical protocol: Viewpoints derived from a joint ENCORA-MARBEF initiative. Oceanologia 49, 579-586;

Derous, T. Agardy, H. Hillewaert, K. Hostens, G. Jamieson, L. Lieberknecht, J. Mees, I. Moul aert, S. Olenin, D. Paelinckx, M. Rabaut, E. Rachor, J. Roff, E.W.M. Stienen, J.T. van der Wal, V. van Lancker, E. Verfaillie, M. Vincx, J.M. Weslawski, S. Degraer (2007). A concept for biological valuation in the marine environment Oceanologia, 49 (1) , pp. 99128

Desvousges, W. H., Gard, N., Michael, H. J., \& Chance, A. D. (2018). Habitat and resource equivalency analysis: A critical assessment. Ecological Economics, 143, 74-89.

Defra. 2019. Net gain. Summary of responses and government response. Department for the Environment, Food and Rural Affairs. July 2019

Dickie I, McAleese L, Pearce B and Treweek J (2013) Marine Biodiversity Offsetting - UK Scoping Study. Report to The Crown Estate. ISBN: 978-1-906410-44-5

Dunford, R. W., Ginn, T. C., \& Desvousges, W. H. (2004). The use of habitat equivalency analysis in natural resource damage assessments. Ecological economics, 48(1), 49-70.

Elliott, M., Borja, A., and Cormier, R. 2020. Activity-footprints, pressures-footprints and effects-footprints - Walking the pathway to determining and managing human impacts in the sea. Marine Pollution Bulletin 155 https://doi.org/10.1016/j.marpolbul.2020.111201

Elliott, M., Burdon, D., Hemingway, K. L., \& Apitz, S. E. (2007). Estuarine, coastal and marine ecosystem restoration: confusing management and science-a revision of concepts. Estuarine, Coastal and Shelf Science, 74(3), 349-366.

Firth LB, Airoldi L, Bulleri F, Challinor S, Chee S-Y, Evans AJ, Hanley ME, Knights AM, O'Shaughnessy K, Thompson RC, Hawkins SJ. (2020). Greening of grey infrastructure should not be used as a Trojan horse to facilitate coastal development. Journal of Applied Ecology. In Press DOI: 10.1111/(ISSN)1365-2664

Firth, L. B., Thompson, R. C., Bohn, K., Abbiati, M., Airoldi, L., Bouma, T. J., ... \& Ferrario, F. (2014). Between a rock and a hard place: environmental and engineering considerations when designing coastal defence structures. Coastal Engineering, 87, 122-135.

Foden, J., Rogers, S. I., \& Jones, A. P. (2009). Recovery rates of UK seabed habitats after cessation of aggregate extraction. Marine Ecology Progress Series, 390, 15-26. 
Griffiths, V. F., Bull, J. W., Baker, J., \& Milner-Gulland, E. J. (2019). No net loss for people and biodiversity. Conservation Biology, 33(1), 76-87.

Hansard, 2009. Daily Hansard - Written Answers 21 October 2009 Column 1460W Marine Aggregates Levy Sustainability Fund.

https://publications.parliament.uk/pa/cm200809/cmhansrd/cm091021/text/91021w0005.ht m Accessed 5 March 2020.

Hattam, C., Atkins, J. P., Beaumont, N., Börger, T., Böhnke-Henrichs, A., Burdon, D., ... \& Sastre, S. (2015). Marine ecosystem services: linking indicators to their classification. Ecological Indicators, 49, 61-75.

HM Government. (2018). A green future: our 25 year plan to improve the environment. London: Department for the Environment Food and Rural Affairs https://www.gov.uk/government/publications/25-year-environment-plan

HM Government. (2017). Industrial Strategy: Building a Britain fit for the future. London: Department for Business, Energy \& Industrial Strategy.

HM Government. (2020). Guidance. A coastal concordat for England (revised: December 2019). Updated 29 January 2020. https://www.gov.uk/government/publications/a-coastalconcordat-for-england/a-coastal-concordat-for-england-revised-december-2019.

Accessed 5 March 2020

HM Government. (2011). The Natural Choice: Securing the Value of Nature. HM Government Natural Environment White Paper. Presented to Parliament by the Secretary of State for Environment, Food and Rural Affairs by Command of Her Majesty. https://www.gov.uk/government/publications/the-natural-choicesecuring-the-value-ofnature.

HM Treasury. (2019). Policy paper. Review of the Aggregates Levy: discussion paper. Updated 27 September 2019. https://www.gov.uk/government/publications/review-of-theaggregates-levy/review-of-the-aggregates-levy-discussion-paper. Accessed 5 March 2020

Hooper, T., Börger, T., Langmead, O., Marcone, O., Rees, S. E., Rendon, O., ... \& Austen, M. (2019). Applying the natural capital approach to decision making for the marine environment. Ecosystem Services, 38, 100947.

Hooper, T., Beaumont, N., \& Hattam, C. (2017). The implications of energy systems for ecosystem services: a detailed case study of offshore wind. Renewable and Sustainable Energy Reviews, 70, 230-241.

IFC. (2019). Performance Standard 6 Biodiversity Conservation and Sustainable Management of Living Natural Resources. January 1, 2012 (updated June 27, 2019). https://www.ifc.org/wps/wcm/connect/topics_ext_content/ifc_external_corporate_site/sust ainability-at-ifc/policies-standards/performance-standards/ps6

Jacob, C., Buffard, A., Pioch, S., \& Thorin, S. (2018). Marine ecosystem restoration and biodiversity offset. Ecological Engineering, 120, 585-594.

Jacob, C., Pioch, S., \& Thorin, S. (2016). The effectiveness of the mitigation hierarchy in environmental impact studies on marine ecosystems: A case study in France. Environmental Impact Assessment Review, 60, 83-98. 
Janßen, H., C. B. Augustin, et al. (2013). Impact of secondary hard substrate on the distribution and abundance of Aurelia aurita in the western Baltic Sea. Marine Pollution Bulletin, 75(1-2): 224-234.

Jennings, S., \& Kaiser, M. J. (1998). The effects of fishing on marine ecosystems. In Advances in marine biology (Vol. 34, pp. 201-352). Academic Press.

Jones, J. P. G., Bull, J. W., Roe, D., Baker, J., Griffiths, V. F., Starkey, M., ... \& MilnerGulland, E. J. (2019). Net Gain: Seeking Better Outcomes for Local People when Mitigating Biodiversity Loss from Development. One Earth, 1(2), 195-201.

Kirby, M. X. (2004). Fishing down the coast: historical expansion and collapse of oyster fisheries along continental margins. Proceedings of the National Academy of Sciences, 101(35), 13096-13099.Armsworth, P. R. (2014). Inclusion of costs in conservation planning depends on limited datasets and hopeful assumptions. Annals of the New York Academy of Sciences, 1322(1), 61-76.

Kirschke, S., \& Newig, J. (2017). Addressing complexity in environmental management and governance. Sustainability, 9(6), 983.

Kyriazi, Z., Lejano, R., Maes, F., \& Degraer, S. (2015). Bargaining a net gain compensation agreement between a marine renewable energy developer and a marine protected area manager. Marine Policy, 60, 40-48.

Levrel, H., Pioch, S., \& Spieler, R. (2012). Compensatory mitigation in marine ecosystems: Which indicators for assessing the "no net loss" goal of ecosystem services and ecological functions?. Marine Policy, 36(6), 1202-1210.

Li, S., Xie, T., Pennings, S. C., Wang, Y., Craft, C., \& Hu, M. (2019). A comparison of coastal habitat restoration projects in China and the United States. Scientific reports, 9(1), 1-10.

Mace, G. M., Hails, R. S., Cryle, P., Harlow, J., \& Clarke, S. J. (2015). Towards a risk register for natural capital. Journal of Applied Ecology, 52(3), 641-653.

Maron, M., Brownlie, S., Bull, J. W., Evans, M. C., von Hase, A., Quétier, F., ... \& Gordon, A. (2018). The many meanings of no net loss in environmental policy. Nature Sustainability, 1(1), 19-27.

Maron, M., Ives, C. D., Kujala, H., Bull, J. W., Maseyk, F. J., Bekessy, S., ... \& Possingham, H. P. (2016). Taming a wicked problem: resolving controversies in biodiversity offsetting. BioScience, 66(6), 489-498.

MHCLG. (2019). National Planning Policy Framework. February 2019. Ministry of Housing, Communities and Local Government.

Mielck, F., Hass, C., Michaelis, R., Sander, L., Papenmeier, S., \& Wiltshire, K. (2019, January). Refill processes and regeneration potential after marine aggregate extraction in the German Bight (SE North Sea). In Geophysical Research Abstracts (Vol. 21).

Milner-Gulland, E. J., Garcia, S., Arlidge, W., Bull, J., Charles, A., Dagorn, L., ... \& Vestergaard, N. (2018). Translating the terrestrial mitigation hierarchy to marine megafauna by-catch. Fish and Fisheries, 19(3), 547-561.

MMO. (2020a). South West Inshore and South West Offshore Marine Plan. Draft for consultation. January 2020 
MMO. (2020b). South West Inshore and South West Offshore Marine Plan. Technical Annex. Draft for consultation. January 2020

Natural Capital Committee. (2019a). Advice to government on net environmental gain. May 2019.

https://assets.publishing.service.gov.uk/government/uploads/system/uploads/attachment_ data/file/801508/ncc-advice-net-enviornmental-gain.pdf

Natural Capital Committee. (2019b) Marine and the 25 Year Environment Plan. https://assets.publishing.service.gov.uk/government/uploads/system/uploads/attachment_ data/file/801512/ncc-advice-marine.pdf

Natural Capital Committee. (2017). How to do it: a natural capital workbook. Version 1. April 2017.

https://assets.publishing.service.gov.uk/government/uploads/system/uploads/attachment_ data/file/608852/ncc-natural-capital-workbook.pdf

Natural England. (2010). Aggregates Levy Sustainability Fund - celebrating success. http://publications.naturalengland.org.uk/file/92017

Nayak, D.R. and Smith, P. (2019). Review and Comparison of Models used for Land Allocation and Nature Valuation Final Report on Phase 1. August 2019. Report for the Landscape Decisions: Towards a new framework for using land assets Programme. https://valuing-nature.net/sites/default/files/images/LAM-Phase-1-Report-44pp_final.pdf

Niner, H. J., Ardron, J. A., Escobar, E. G., Gianni, M., Jaeckel, A., Jones, D. O., ... \& Van Dover, C. L. (2018). Deep-sea mining with no net loss of biodiversity-an impossible aim. Frontiers in Marine Science, 5, 53.

Niner, H. J., Milligan, B., Jones, P. J., \& Styan, C. A. (2017a). A global snapshot of marine biodiversity offsetting policy. Marine Policy, 81, 368-374.

Niner, H. J., Milligan, B., Jones, P. J., \& Styan, C. A. (2017b). A global snapshot of marine biodiversity offsetting policy. Marine Policy, 81, 368-374.

ONS. (2019). UK natural capital accounts: 2019. Estimates of the financial and societal value of natural resources to people in the UK. Release date: 18 October 2019. https://www.ons.gov.uk/economy/environmentalaccounts/bulletins/uknaturalcapitalaccoun ts/2019\#regulating-services

Pauly D 1995 Anecdotes and the shifting baseline syndrome of fisheries. Trends in Ecology and Evolution 10, 430

Pereira, C. I., Carvajal, A. F., Batista, C. M., \& Botero, C. M. (2019). Regulating human interventions in Colombian coastal areas: Implications for the environmental licensing procedure in middle-income countries. Environmental Impact Assessment Review, 79, 106284

Prusina, I., Hermans, A., and Bos, O.G. 2020. Nature-Inclusive Design: a catalogue for offshore wind infrastructure. Report prepared by Witteveen+Boss and Wageningen University \& Research for the Ministry of Agriculture, Nature and Food Quality. https://www.wur.nl/upload_mm/4/c/1/b63af7c4-c405-429d-b5d4a7cffc2fce81_Appendix\%20III_NID\%20catalogue.pdf 
Quétier, F., Regnery, B., \& Levrel, H. (2014). No net loss of biodiversity or paper offsets? A critical review of the French no net loss policy. Environmental Science \& Policy, 38, 120131.

Rees, S.E., Sheehan, E.V., Stewart, B.D., Clark, R., Appleby, T., Attrill, M.J., Jones, P.J.S., Johnson, D., Bradshaw, N., Pittman, S., Oates, J. and Solandt, J-L. (2020). Emerging themes to support ambitious UK marine biodiversity conservation. Marine Policy 103864

Rees, S.E., Ashley, M., Cameron, A. (2019). North Devon Marine Pioneer 2: A Natural Capital Asset and Risk Register. A SWEEP/WWF-UK report by research staff the Marine Institute at the University of Plymouth

Rio Tinto. (2008). Rio Tinto and biodiversity: Achieving results on the ground. www. riotinto. com/documents/ReportsPublications/RTBidoversitystrategyfinal. pdf.

Rist, L., Campbell, B. M., \& Frost, P. (2013). Adaptive management: where are we now? Environmental conservation, 40(1), 5-18.

Shumway, N., Watson, J. E., Saunders, M. I., \& Maron, M. (2018). The risks and opportunities of translating terrestrial biodiversity offsets to the marine realm. BioScience, 68(2), 125-133.

Tallis, H., Kennedy, C. M., Ruckelshaus, M., Goldstein, J., \& Kiesecker, J. M. (2015). Mitigation for one \& all: An integrated framework for mitigation of development impacts on biodiversity and ecosystem services. Environmental Impact Assessment Review, 55, 21 34.

Thurstan, R. H., Hawkins, J. P., Raby, L., \& Roberts, C. M. (2013). Oyster (Ostrea edulis) extirpation and ecosystem transformation in the Firth of Forth, Scotland. Journal for nature conservation, 21(5), 253-261.

Vaissière, A. C., Levrel, H., Pioch, S., \& Carlier, A. (2014). Biodiversity offsets for offshore wind farm projects: The current situation in Europe. Marine Policy, 48, 172-183.

Van Tatenhove, J. (2011). Integrated marine governance: questions of legitimacy. Mast, 10(1), 87-113.

Vardon, M., Bass, S., Ahlroth, S., and Ruijs, A. (2017). Forum on Natural Capital Accounting for Better Policy Decisions: Taking Stock and Moving Forward. World Bank. Wealth Accounting and the Valuation of Ecosystem Services, Washington D.C.

Walker, R., and Judd, A. (2010). Strategic review of offshore wind farm monitoring data associated with FEPA licence conditions. Centre for Environment, Fisheries, and Aquaculture Science.

Walker, R., Judd, A, Warr, K, Doria, L., Pacitto, S., Vince, S., and Howe, L. (2009). Strategic review of offshore wind farm monitoring data associated with FEPA licence conditions. Report by Centre for Environment Fisheries and Aquatic Science (CEFAS); 2009.

White, M. P., Alcock, I., Grellier, J., Wheeler, B. W., Hartig, T., Warber, S. L., ... \& Fleming, L. E. (2019). Spending at least 120 minutes a week in nature is associated with good health and wellbeing. Scientific reports, 9(1), 1-11.

Wilkinson, J. (2009). In-lieu fee mitigation: coming into compliance with the new Compensatory Mitigation Rule. Wetlands ecology and management, 17(1), 53-70. 
Wind Europe. (2020). Offshore Wind in Europe. Key trends and statistics 2019. February 2020. https://windeurope.org/about-wind/statistics/offshore/european-offshore-windindustry-key-trends-statistics-2019/ 